\title{
Separation Behavior for Parturition of Red Angus Beef Cows
}

\author{
Cornelia Flörcke, Temple Grandin \\ Department of Animal Sciences, Colorado State University, Fort Collins, USA \\ Email: conny.floe@gmx.de, cheryl.miller@colostate.edu
}

Received 20 January 2014; revised 28 February 2014; accepted 9 March 2014

Copyright (C) 2014 by authors and Scientific Research Publishing Inc.

This work is licensed under the Creative Commons Attribution International License (CC BY). http://creativecommons.org/licenses/by/4.0/

(c) $\underset{\mathrm{EY}}{\mathrm{B}}$ Open Access

\section{Abstract}

Increased predation losses in beef cattle in the Northern Rocky Mountains raise the importance of research concerning maternal behavior around the time of parturition. Separation behavior of multiparous cows at parturition was studied by measuring the distance $(\mathrm{m})$ between the birth place and the main herd with a GPS device. Age of cows and forehead hair whorl pattern (HW) were analyzed as possible factors affecting separation distance. A total of 333 cows $(95 \%$ Red Angus and 5\% Angus $\times$ Hereford commercial crossbreds; age range: 3 - 6 yrs) were studied. Separation distance was determined by approaching the cow-calf pair with a utility vehicle that gradually decreased the distance to the pair. The geographic coordinates per pair were recorded and the separation distance was calculated as a straight line between each pair and the main herd. The HW on the forehead of each animal was used as a measure of individual differences in temperament. Age and HW were collected when the animals were held in a squeeze chute. HW was classified into one of six groups: high, middle, low, abnormal, multiple HWs and no HW. The age of a cow influenced the separation distance for parturition $(P<0.001)$. Four-year-old cows were on average about $150 \mathrm{~m}$ further away than other aged cows when calving. Eighty-eight percent of cows separated more than $100 \mathrm{~m}$ from the herd. The hair whorl position had no influence on the separation distance $(P=0.405)$. Distinct separation behavior for parturition was observed in this herd which appears to be an innate behavior that is influenced by the individual temperament of the cow.

\section{Keywords}

Cattle; Hair Whorl Pattern; Parturition; Selection; Temperament

\section{Introduction}

In ungulates, when a cow approaches parturition, there are two distinctively different behaviors that can be ob- 
served. One is aggregation behavior, which is observed in saiga antelope (Saiga tatarica; [1]) and wildebeests (Connochates taurinus; [2]) which is often influenced by resource availability and predator presence. The other is separation behavior which is observed in caribou (Rangifer tarandus; [3]) and moose (Alces alces gigas; [4]) in which females move away from the herd to give birth unaccompanied. Aggregation behavior is effective because other females will cooperate in defending the group against the predator. Separation behavior is effective because predators have greater difficulty locating the parturient dam. Leuthold, 1977 [5] suggested that maternal isolation at calving reduces the risk of predation and facilitates imprinting between the cow and her newborn calf.

The investigation of maternal protectiveness towards the calf after parturition has become of increasing importance since the reintroduction of gray wolves in the Northern Rocky Mountains [6]. A study by Flörcke et al. 2012 [7] investigated maternal protectiveness and calf defense patterns of cows $24 \mathrm{~h}$ after parturition and found that cows vary in their level of vigilance towards their surroundings. Vigilance is associated with the temperament of the cow and can be directly linked to the survival chances of the calf. It has been found that cows without a facial hair whorl are $20 \%$ more likely to lose their calf compared to cows with facial HWs [8]. The separation for parturition represents a potential risky situation for cow and calf as well as for producers. Steadily increasing losses due to predation have been observed [9]. Learning more about parturition behavior in cows may assist ranchers in reducing predation.

In cattle, Lidfors et al. 1994 [10] reported large individual differences in separation behavior between parturient cows which was further influenced by the type of environment. In forest, areas, cows exhibit shelter seeking behavior similar to wild relatives. In open areas without trees, soft dry bedding seemed to be the most important factor and calving occurred at random places. Individual differences, also referred to as temperament or personality, can be used to predict behaviors in unfamiliar environments and these differences are heritable and consistent over time [11]-[13]. The spiral HW on the forehead of a cow can be used as a predictor of the individual temperament of the animal [14] [15]. Cows with higher HW positions are more excitable and more easily agitated during restraint [14]. Maternal vigilance of animals with a high HW is greater than vigilance behavior in animals with a lower HW position. These cows pay more attention to their surroundings and they perceive threats earlier [7]. In horses, there is an association between the facial HW and motor behaviors [16]. Horses with a spiral HW that turns counter-clockwise tend to be left-lateralized and horses with clockwise HW are more likely to be right-lateralized. In addition, there is an association between visual laterality and emotions [17]. Laterality was shown when the mares were confronted with a familiar positive-, a novel- and a negative object. Mares preferred to use their right eye to look at the novel object and their left eye to investigate the negative object [17].

In this study, we examined the possible influence of the HW and age of the dam on separation distance from the herd for parturition. We further investigated if the rotation of the spiral HW (clockwise/counter-clockwise/radiant) had an effect on separation distance. Within the first $24 \mathrm{~h}$ after parturition, the separation distance of cows was recorded and analyzed. Understanding maternal and separation behaviors around the time of parturition may help ranchers reduce predation losses in the future.

\section{Material and Methods}

Observations were made in compliance with Colorado State University Animal Care and Use Committee Protocol IACUC \# 10-2267A.

\subsection{Animals and Environment}

This study was conducted on a commercial Red Angus cow-calf ranch near Byers, Colorado, USA, in 2011. Calving season started in early February and lasted until June, 2011. Ninety-five percent of cows were commercial Red Angus and the remaining 5\% were Red Angus $\times$ Hereford commercial crossbreds. Free-ranging multiparous cows (total herd: $\mathrm{N}=836 ; 3-6$ years of age), maintained in an open pasture were used. Cows on this ranch calved for the first time as 2-year-old heifers while housed in a small pen where they were observed closely at all times. Two-year-old heifers were not included in the study due to differences in handling and pen size. The 3-year-old cows were turned out with the older cows on a big pasture and calved unobserved for the first time. The single pasture was approximately 320 ha with undulating hills, small bushes (height: $40-60 \mathrm{~cm}$ ) and sandy soil but no trees. The pasture had a rectangular layout with one narrow corner on the north side 
(Figure 1). Cows were fed corn stalks each morning between 0800 - $1000 \mathrm{~h}$ and had unlimited access to water from water troughs. Each day, cows that were pregnant, or had a calf that was able to walk on its own would all aggregate in the morningaround the feeding ground. This facilitated identification of parturient cows which would separate from the herd (minimum distance $=25 \mathrm{~m}$ to be included in study). Cows that calved closer than $25 \mathrm{~m}$ to the herd were not included in the study. The main predators on this ranch were coyotes. Coyotes were sighted on multiple occasions consuming afterbirth but did not kill any livestock during the observed calving season of 2011. However, during several previous calving seasons, predation losses were recorded and cows had experienced the presence of predators.

\subsection{Cow Age and Hair Whorl Pattern (HW) Collection}

Age and HW on the forehead of all cows were recorded while cows were in a squeeze chute for pregnancy diagnoses. The experimenter identified the HW position and drew it on a piece of paper. Hair whorls were classified as being high, middle or low position. Using the eye-line as a reference point, HW were further classified as being abnormal, multiple (more than one, all with a clear center) or none (no HW on forehead). Examples of the HW drawings are shown in Figure 2. Classifications are mutually exclusive and animals were classified into one of these six groups.

\subsection{Global Positioning System (GPS) Data Collection}

GPS data were collected from Febr. 16 th $^{\text {th }}$ Apr. $6^{\text {th }}$, 2011 during the main calving season utilizing a Garmin GPS

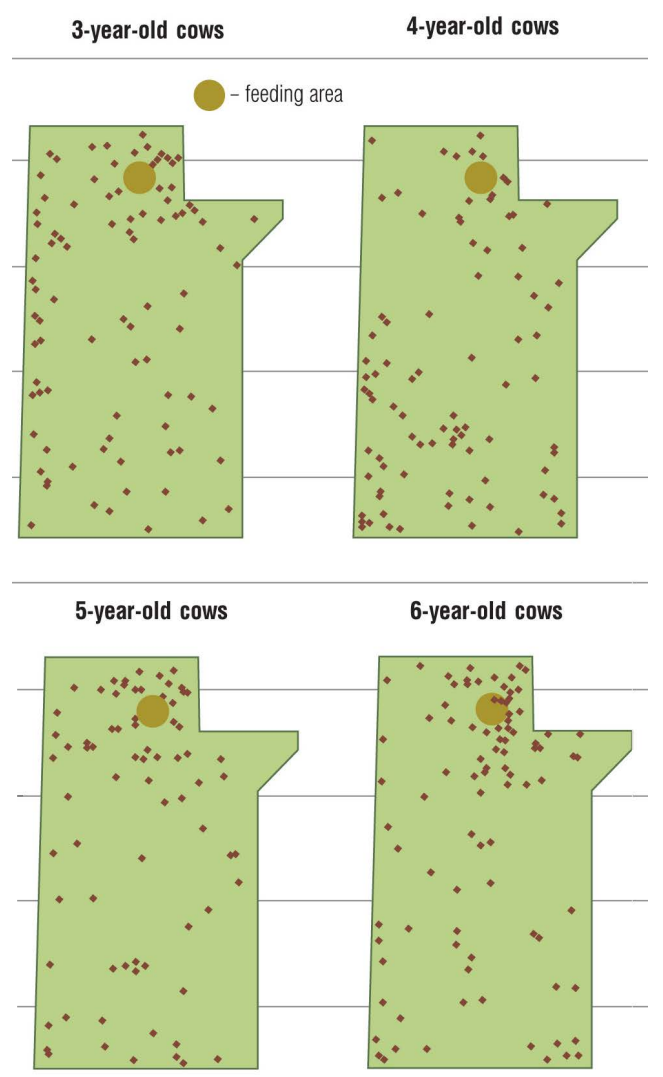

Figure 1. Geographic coordinates of each cow-calf pair on the pasture, separated by age. The width is approximately $900 \mathrm{~m}$ at the widest point and the length is approximately $1200 \mathrm{~m}$. Each diamond represents the parturition side of one cow-calf pair. Coordinates were collected from Febr. $16^{\text {th }}-$ Apr. $6^{\text {th }}$, 2011 during the main calving season. 
(a)

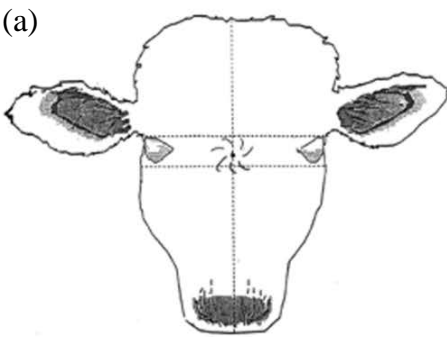

(c)

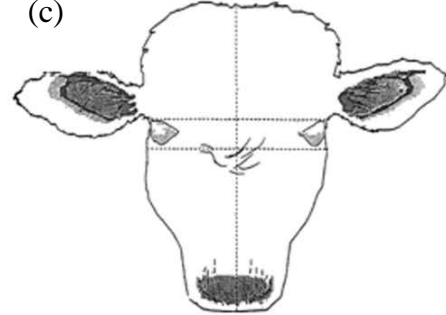

(e)

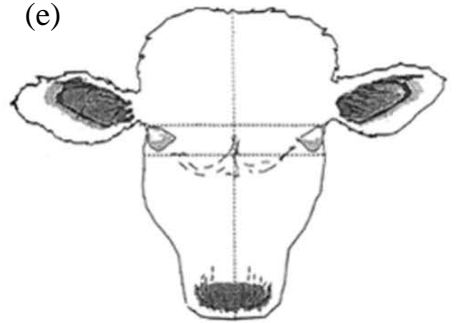

(g)

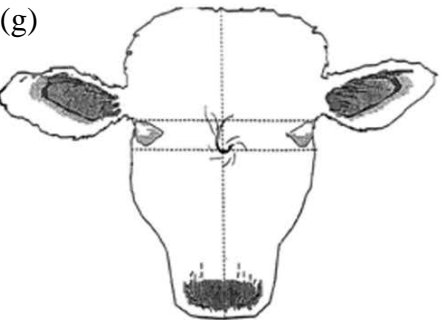

(b)

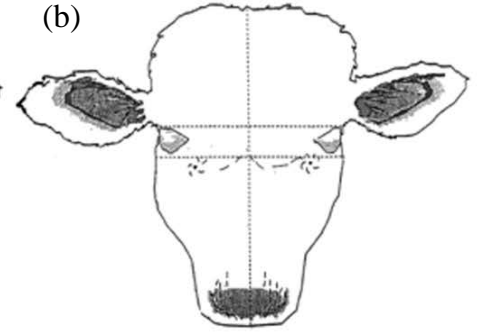

(d)
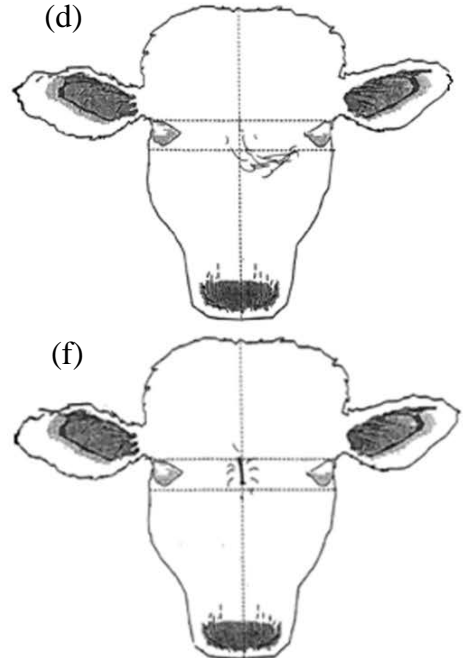

(h)

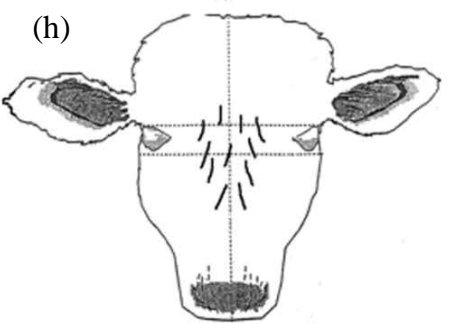

Figure 2. Description of the six hair whorl patterns (HW): (a) A normal middle HW with a clear center and a spiral pattern. Low and high HW would look like this, too with the low HW being below the lower eye-line and the high HW being above the upper eye-line. (b) An example of multiple, spiral HW of the forehead, each with a clear center. (c) to (g) Examples of abnormal HWs; (c) One single flair starting under the right eye of the animal growing towards the middle. (d) One single flair starting under the left eye of the animal growing towards the middle. (e) A double flair starting under each eye. (f) A long vertical line on the forehead with no spiral pattern. (g) Every other form like a sickle or curved vertical line. (h) No HW and all the hair lays straight down.

device to locate the position of cow and calf on the pasture (Manufacturer: Garmin etrex H Yellow, Garmin International Inc., Olathe, KS, USA). Data collection started at $0800 \mathrm{~h}$ every morning and lasted up to $4 \mathrm{~h}$. During this time, the main herd would aggregate around the feeding ground. The center of the feeding ground was used as a reference point for GPS calculations. All separation distances were calculated as a straight line to the center point. All cow-calf pairs were approached within the first $24 \mathrm{~h}$ after parturition when the pairs' mobility was lowest. To obtain data on the distance between the feeding area and the parturition site, the cow and her newborn calf were spotted with binoculars on the pasture. Each cow-calf pair was approached with a utility vehicle (gray GMC Jimmy) which gradually decreased the distance to the cow-calf pair (range of speed during approach: $8-16 \mathrm{~km} / \mathrm{h}$ [7]. This approach occurred only once per pair. Separation data was obtained for 333 cow-calf pairs 
after parturition. Collecting data on more animals was logistically not possible since some cows calved at night or could not be found during the day. Interferences with other cows while performing the observations did not occur due to the large size of the pasture and the natural separation behavior of cows. The maximum distance a cow could separate from the herd before parturition was $1250 \mathrm{~m}$.

\subsection{Statistical Analyses}

Data were normally distributed and variance was homogeneous (Levene's test). Analysis of variance was conducted using SPSS 17.0 (SPSS, Inc.) with separation distance as the dependent variable and age, HW and HW rotation as factors. We discovered an effect of age on separation distance $(P<0.05)$ and thus conducted a post-hoc protected Fisher's LSD test to determine differences between each combination of age groups ( 3 vs. 4 , 3 vs. 5,3 vs. 6,4 vs. 5,4 vs. 6 and 5 vs. 6 ). The significance level was set to $P<0.05$ for this study and graphs show mean values with standard error bars.

\section{Results}

The separation distance for parturition ranged from $25 \mathrm{~m}$ to $1250 \mathrm{~m}$. Hollows with sandy soil surrounded by small bushes were preferred for calving. The cows in our study spent approximately 12 to 24 hrs at the parturition site. A total of $95.2 \%(n=317)$ of cows separated further than $50 \mathrm{~m}$ from the feeding area where the main herd was located, $88.3 \%(n=294)$ separated further than $100 \mathrm{~m}$ for parturition. The age of a cow greatly influenced the separation distance for parturition $(P<0.001$, Figure 3$)$. Four-year-old cows separated on average $714 \mathrm{~m}( \pm \mathrm{SE} 38.3 \mathrm{~m})$ from the main herd whereas the other aged cows (3, 5 and 6 years) separated $508 \mathrm{~m} \pm \mathrm{SE}$ $23.5 \mathrm{~m}$. To visualize the spatial distribution behavior of cows on the pasture when separating from the herd we plotted the geographic coordinates for each cow-calf pair, separated by age of the cow (Figure 1). Only one cow within the observed herd calved in a narrow corner (age 3, latitude: 39,893, longitude: 104,052). The HW of cows had no influence on the separation behavior $(P=0.405)$ and there was no association between the HW rotation and separation distance $(P=0.782)$.

\section{Discussion}

We were able to show the active separation behavior of Red Angus beef cows before parturition. Since differences in temperament influence the separation distance it is not surprising to see that the separation distance varied between 25 and $1250 \mathrm{~m}$. Several researchers reported that separation behavior is influenced by the environment. In open environments with few trees, females of many wild ungulate species tend to aggregate in large

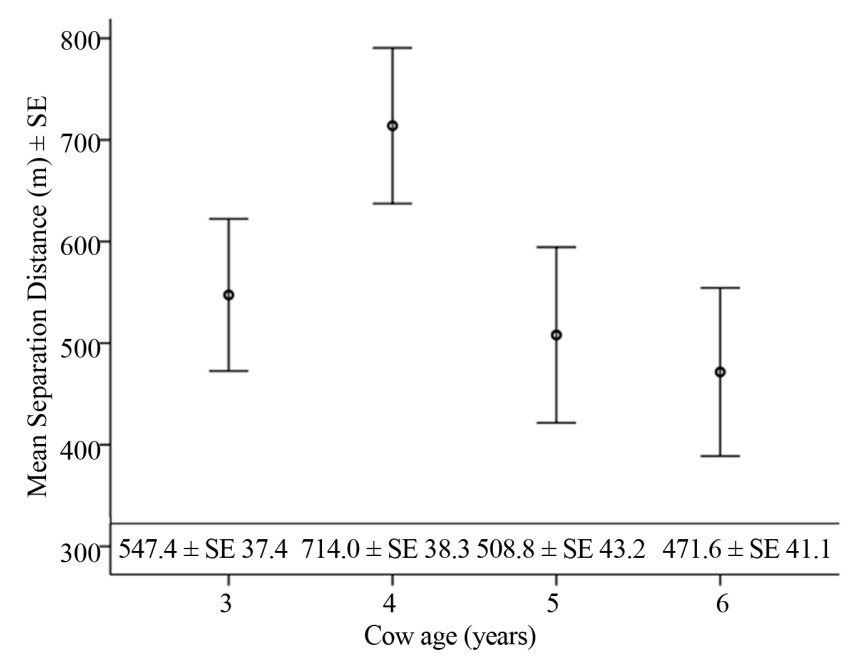

Figure 3. Mean separation distance (m) of cows after parturition from the main herd and the feeding area, classified by the age of cows. Included are mean values per age group $\pm \mathrm{SE}$ (age $3, \mathrm{n}=85$; age 4, $n=86$; age 5, $n=73$; age $6, n=89$ ). 
numbers to give birth. This may serve as a confusion strategy against predators [1] [2] [18]. In forest environments, ungulate females tend to seek isolation either in woody vegetation or tall grasses [5] [19] and American Bison prefer cover by oak trees [20].

The difference between wild ungulates and our study is that the cows were fed every morning at the same location. This influenced their dispersal behaviors. Before parturition, 88\% of cows actively separated more than $100 \mathrm{~m}$ from the main herd and the feeding area. Our findings are in agreement with the model of Barbknecht $e t$ al. 2011 [21]. Their model predicts that females should select parturition sites based on the features of the macro- and microhabitat. The macrohabitat represents topographical and vegetative cover for physical and thermal protection such as hill and groups of trees and the microhabitat provides visual cover due to hollows or bushes. We found that visual cover formed by bushes and hollows was highly preferred over more open spaces for parturition.

The availability and selection of cover may have altered the time spent at the parturition site [22]. Since smaller bushes provide less cover and protection it might be favorable for the cow-calf pair to leave the parturition site earlier, whereas more time can be spent if better protection is available. However, even the short time period of separation allowed for undisturbed parturition andallowed the formation of the cow-calf bond. Leaving the birth site shortly after parturition may have corresponded with higher calf survival, as has been found in a similar study in woodland caribou (Rangifer tarandus) [23].

The age of cows had a significant effect on separation distance. With an age range of 3 - 6 years, cows on this ranch were relatively young. The 2-year-old heifers (first time calving; not included in the study) may have had a less well developed mother-young bond due to the limited space for parturition in the pen and separation behavior was impossible. Three-year-old cows calved unobserved on the big pasture for the first time. Separation behavior may have been less likely in these cows because they had previously calved in a small pen. Aberrant maternal behaviors have been found in inexperienced mothers [24]. It is interesting to look at the spatial distribution of all the cows in this study (Figure 1). Only one 3-year-old individual chose to calve in a narrow corner which may represent a trap in case of predation presence. This may be due to inexperience. The 4-year-old cows which calved on the pasture for the second time had the greatest separation distance. Based on life history characteristics associated with parturition cows may be more vigilant towards their surroundings to assure protection of the calf [7] and the separation behavior may help imprinting between cow-and calf [5]. Lent 1974 [25] found that parturition frequently attracts other conspecifics and even males which may lead to less well developed mother-young bonds [26]-[28] and licking by conspecifics can even lead to desertion of the newborn calf [26]. Therefore, the separation of 4-year-old cows may represent a learning process to guarantee a close mother-young bond and improved protection. However, in areas with high predation this behavior may be disadvantageous in terms of predation pressure and we would recommend keeping parturient cows in close proximity to the barn, if possible. Cows that are older than four years are likely more dominant because they are full grown and established their social rank in the herd. These cows can calve in closer proximity of the herd and chase away younger cows to prevent licking of the newborn calf [28] and still develop a strong mother-young bond. Separation of younger cows may be a defensive strategy [29] to guarantee the maternal bond without being interrupted during parturition. Further studies should be conducted in an area with wolf predation to assess possible differences in separation and maternal behavior of cows in different predation environments.

The temperament of the cow, measured by the HW position and rotation, did not influence the separation distance. It has been found that animals with higher HWs tend to be easily agitated [14] and that cows with higher HWs are more vigilant towards their surroundings [7] but this was not reflected in an increased separation distance.

\section{Conclusion}

We observed distinct separation behavior before parturition from the main herd (Red Angus and Red Angus $\times$ Hereford commercial crossbreds). We suggest that the short-time period of separation for parturition probably allowed for a greater separation distance and additionally improved imprinting between cow and calf even though predation risk may be increased. Four-year-old cows moved the furthest away from the herd and overall, $88 \%$ of cows separated more than $100 \mathrm{~m}$ from the feeding area. No effect of temperament, measured by the spiral HW on the forehead of cows, on separation distance for parturition was found. Maternal behaviors around the time of parturition have become of increasing importance and need to be included in selection programs to 
maintain sustainability for ranchers in areas with high predation.

\section{Acknowledgements}

We are grateful for the collaboration with Bradbury Land and Cattle, Byers, CO, including all staff and especially the owner, Tom Bradbury. Mikaela Vetters is thanked for her time collecting hair whorl data and Jim Zum Brunnen for his statistical advice and discussions.

\section{References}

[1] Singh, N.J., Grachev, I.A., Bekenov, A.B. and Milner-Gulland, E.J. (2010) Saiga Antilope Calving Site Selection is Increasingly Driven by Human Disturbance. Biological Conservation, 143, 1770-1779. http://dx.doi.org/10.1016/j.biocon.2010.04.026

[2] Estes, R.D. (1976) The Significance of Breeding Synchrony in the Wildebeest. African Journal of Ecology, 14, 135152. http://dx.doi.org/10.1111/j.1365-2028.1976.tb00158.x

[3] Rettie, W.J. and Messier, F. (2001) Range Use and Movement Rates of Woodland Caribou in Saskatchewan. Canadian Journal of Zoology, 79, 1933-1940. http://dx.doi.org/10.1139/z01-156

[4] Bowyer, R.T., van Ballenberghe, V., Kie, J.G. and Maier, J.A.K. (1999) Birth-Site Selection by Alaskan Moose: Maternal Strategies for Coping with a Risky Environment. Journal of Mammalogy, 80, 1070-1083. http://dx.doi.org/10.2307/1383161

[5] Leuthold, W. (1977) African Ungulates. A Comparative Review of Their Ethology and Behavioral Ecology. Springer Verlag, Berlin, Heidelberg, New York, 158-168.

[6] Bangs, E.E. and Fritts, S.H. (1996) Reintroducing the Gray Wolf to Central Idaho and Yellowstone National Park. Wildlife Society Bulletin, 24, 402-413.

[7] Flörcke, C., Engle, T.E. and Grandin, T. (2012) Individual Differences in Calf Defence Patterns in Red Angus Beef Cows. Applied Animal Behaviour Science, 139, 203-208. http://dx.doi.org/10.1016/j.applanim.2012.04.001

[8] Flörcke, C. and Grandin, T. (2013) Loss of Anti-Predator Behaviors in Cattle and the Increased Predation Losses by Wolves in the Northern Rocky Mountains. Open Journal of Animal Sciences, 3, 248-253. http://dx.doi.org/10.4236/ojas.2013.33037

[9] Clark, P.E. and Johnson, D.E. (2009) Wolf-Cattle Interactions in the Northern Rocky Mountains. In: Range Field Data 2009 Progress Report. Special Report 1092. Oregon State University. Agricultural Experiment Station, Corvallis, 1-7.

[10] Lidfors, L.M., Moran, D., Jung, J., Jensen, P. and Castren, H. (1994) Behaviour at Calving and Choice of Calving Place in Cattle Kept in Different Environments. Applied Animal Behaviour Science, 42, 11-28. http://dx.doi.org/10.1016/0168-1591(94)90003-5

[11] Morris, C.A., Cullen, N.G., Kilgour, R. and Bremner, K.J. (1994) Some Genetic Factors Affecting Temperament in Bos Taurus Cattle. New Zealand Journal of Agricultural Research, 37, 167-175. http://dx.doi.org/10.1080/00288233.1994.9513054

[12] Gauly, M., Mathiak, H., Hoffman, K., Kraus, M. and Erhardt, G. (2001) Estimating Genetic Variability in Temperamental Traits in German Angus and Simmental Cattle. Applied Animal Behaviour Science, 74, 109-119. http://dx.doi.org/10.1016/S0168-1591(01)00151-4

[13] Dingemanse, N.J., Both, C., Drent, P.J., van Oers, K. and van Noordwijk, A.J. (2002) Repeatability and Heritability of Exploration Behaviour in Great Tits from the Wild. Animal Behaviour, 64, 929-938. http://dx.doi.org/10.1006/anbe.2002.2006

[14] Grandin, T., Deesing, M.J., Struthers, J.J. and Swinker, A.M. (1995) Cattle with Hair Whorl Patterns above the Eyes Are More Behaviorally Agitated during Restraint. Applied Animal Behaviour Science, 46, 117-123. http://dx.doi.org/10.1016/0168-1591(95)00638-9

[15] Randle, H.D. (1998) Facial Hair Whorl Position and Temperament in Cattle. Applied Animal Behaviour Science, 56, 139-147. http://dx.doi.org/10.1016/S0168-1591(97)00086-5

[16] Murphy, J. and Arkins, S. (2008) Facial Hair Wholrs (Trichoglyphs) and the Incidensce of Motor Laterality in the Horse. Behavioural Processes, 79, 7-12. http://dx.doi.org/10.1016/j.beproc.2008.03.006

[17] De Boyer Des Roches, A., Richard-Yris, M.-A., Henry, S., Ezzaouïa, M. and Hausberger, M. (2008) Laterality and Emotions: Visual Laterality in the Domestic Horse (Equus caballus) Differs with Objects' Emotional Value. Physiology \& Behavior, 94, 487-490. http://dx.doi.org/10.1016/j.physbeh.2008.03.002

[18] Milner-Gulland, E.J. (2001) A Dynamic Game Model for the Decision to Join an Aggregation. Ecological Modelling, 145, 85-99. http://dx.doi.org/10.1016/S0304-3800(01)00381-7 
[19] Tulloch, D.G. (1979) The Water Buffalo, Bubalus bubalis, in Australia: Reproductive and Parent-Offspring Behaviour. Australian Wildlife Research, 6, 265-287. http://dx.doi.org/10.1071/WR9790265

[20] Lott, D.F. and Galland, J.C. (1985) Parturition in American Bison: Precocity and Systematic Variation in Cow Isolation. Zeitschrift für Tierpsychologie, 69, 66-71. http://dx.doi.org/10.1111/j.1439-0310.1985.tb00757.x

[21] Barbknecht, A.E., Fairbanks, W.S., Rogerson, J.D., Maichak, E.J., Scurlock, B.M. and Meadows, L.L. (2011) Elk Parturition Site Selection at Local and Landscape Scales. The Journal of Wildlife Management, 75, 646-654. http://dx.doi.org/10.1002/jwmg.100

[22] Barten, N.L., Bowyer, R.T. and Jenkins, K.J. (2001) Habitat Use by Female Caribou: Tradeoffs Associated with Parturition. The Journal of Wildlife Management, 65, 77-92. http://dx.doi.org/10.2307/3803279

[23] Gustine, D.D., Parker, K.L., Lay, R.J., Gillingham, M.P. and Heard, D.C. (2006) Calf Survival of Woodland Caribou in a Multi-Predator Ecosystem. Wildlife Monographs, 165, 1-32. http://dx.doi.org/10.2193/0084-0173(2006)165[1:CSOWCI]2.0.CO;2

[24] Price, E.O., Thos, J. and Anderson, G.B. (1981) Maternal Responses of Confined Beef Cattle in Single versus Twin Calves. Journal of Animal Science, 53, 934-939.

[25] Lent, P.C. (1974) Mother-Infant Relationships in Ungulates. The Behavior of Ungulates and Its Relationship to Management. IUCN Publications, Morges, 14-55.

[26] Edwards, S.A. (1983) The Behaviour of Dairy Cows and Their Newborn Calves in Individual or Group Housing. Applied Animal Ethology, 10, 191-198. http://dx.doi.org/10.1016/0304-3762(83)90140-2

[27] Owens, J.L., Edey, T.N., Bindon, B.M. and Piper, L.R. (1985) Parturient Behaviour and Calf Survival in a Herd Selected for Twinning. Applied Animal Behaviour Science, 13, 321-333. http://dx.doi.org/10.1016/0168-1591(85)90012-7

[28] Illmann, G. and Spinka, M. (1993) Maternal Behaviour of Dairy Heifers and Suckling of Their Newborn Calves in Group Housing. Applied Animal Behaviour Science, 36, 91-98. http://dx.doi.org/10.1016/0168-1591(93)90001-6

[29] Rubenstein, D.I. (1978) On Predation, Competition and the Advantages of Group Living. Perspectives in Ethology, 3, 205-231. http://dx.doi.org/10.1007/978-1-4684-2901-5_9 